\title{
Emmert's imaginal law
}

\author{
GREGORY R. LOCKHEAD and NANCY J. EVANS \\ Duke University, Durham, North Carolina 27706
}

\begin{abstract}
The apparent size of a visual afterimage increases in proportion with the distance at which that image is viewed; this is Emmert's law. Contrary to Emmert's law for afterimages, this paper reports that the apparent size of a mentally imaged object decreases monotonically with increases in the distance of the viewing surface.
\end{abstract}

In 1881, Emil Emmert reported that the apparent size of a visual afterimage is directly proportional to the distance between the observer and the surface on which that image is seen. Emmert had observers obtain an afterimage by prolonged viewing of a bright object. He then had them project that image within a square black frame on a white surface. The framed area was changed in size and distance, and Emmert found, as an example, that an afterimage perceived to just fit in a $2 \times 2 \mathrm{~cm}$ frame at $1 \mathrm{~m}$ viewing distance fit equally well into a $4 \times 4 \mathrm{~cm}$ frame at $2 \mathrm{~m}$. The formal statement of this proportionality, that image size $\propto$ (object size/object distance) $\times$ (image distance), is known as Emmert's law.

Afterimages are but one of a family of mental images that have measurable aspects. Similarity and response times have been the primary dependent variables for most other empirical imagery studies. For example, the similarity judgments between real and imagined objects are essentially identical (Shepard, 1978); the time required to rotate an internally generated mental image increases with amount of rotation (Shepard \& Metzler, 1971); and the time to report about some aspect of a mental image depends on the distance of that aspect from another attended aspect (Kosslyn, 1975).

We have begun study of a third dependent variable, that of size. To learn if there is a lawful relation between the perceived size of an internally generated mental image and the perceived distance of that image, we modified Emmert's study. Rather than ask observers to stare at a bright object until an afterimage was obtained and then to view that afterimage on a screen that would be moved, we asked them to imagine an object on the screen and to describe any changes in this image when the viewing distance of the screen changed.

We thank Lynn Collins for assistance in data collection and Herb Crovitz and Mike King for their critical comments.

\section{STUDY 1: IMAGE THE APPLE}

A student sat before a $101.6 \mathrm{~cm}$ (40 in.) high $\times$ $76.2 \mathrm{~cm}$ (30 in.) wide white screen, in a normally lighted room, and was asked to "come up with a visual image, to visually imagine" an apple within an area (diameter $=30 \mathrm{~cm}$ ) of the screen which the experimenter outlined by pointing. The viewing screen was blank. It was not possible to use a grid, as Emmert did when measuring afterimages, because observers complained that markings on the screen made an image difficult or impossible to maintain. Some students reported the task was not possible, and 30 people were tested to obtain the targeted 20 naive observers.

The screen was initially viewed at one of three starting positions. These were $75 \mathrm{~cm}, 150 \mathrm{~cm}$, and $225 \mathrm{~cm}$ from the observer. Once the observer reported an image, she/he was told to concentrate on it throughout the study and that the screen was about to move. The screen then moved smoothly, at about $20 \mathrm{~cm} / \mathrm{sec}$, from 75 to $225 \mathrm{~cm}, 225$ to 75,150 to 75 , or 150 to 225; there were five observers in each of these four conditions. When the screen stopped, "any changes" in the appearance of the imaged apple were asked for, and the image size was estimated by the experimenter's placing her hands at the extreme top and bottom of the screen and asking the observer to instruct the hand movements until the hands "just contained" the apple. This task was surprisingly easy for the observers, who also had no difficulty talking while observing the image. Then the screen moved its full extent, from 75 to $225 \mathrm{~cm}$, or from 225 to $75 \mathrm{~cm}$; the observers again described any changes, and again the image size was estimated. All observers reported they could maintain the image throughout the study.

The mean image height is shown as the lower function in Figure 1. On average, the image was smaller when the screen was further away and larger when up close. (One estimate, recorded as the screen height, was that the image was larger than the screen when it came close; the image overflowed 


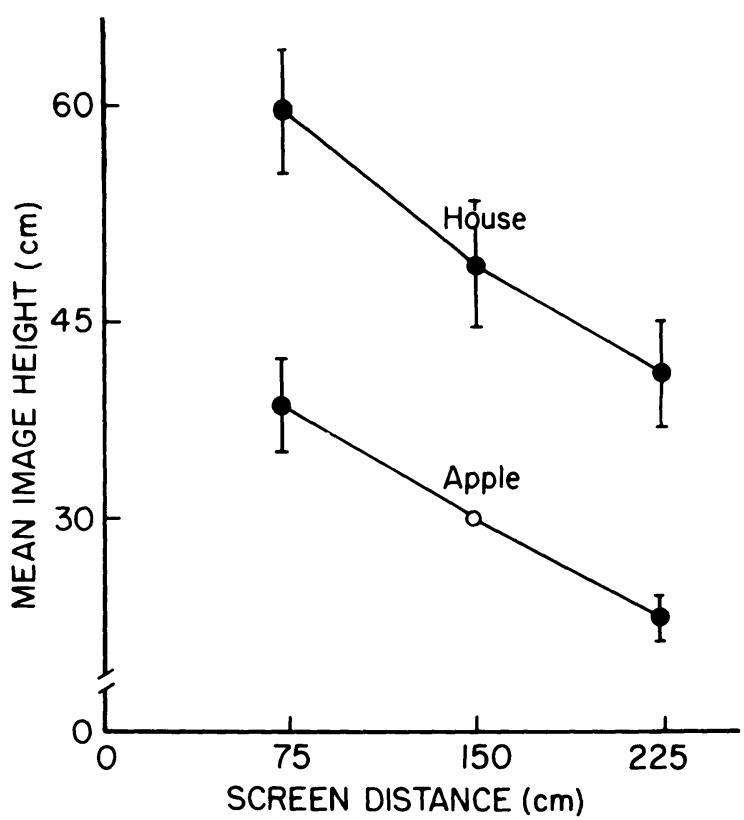

Figure 1. Mean image height as a function of screen distance for Study 1 (lower function) and for Study 2 (upper function). The open circle indicates the instructed initial image size for Study 1. Bars indicate the standard error about each point.

the screen.) This pattern of smaller when far away and larger when up close ocurred for 18 of the 20 observers.

Sometimes expressing surprise, 16 observers also spontaneously verbalized the image size changes reflected in Figure 1. Perhaps most striking is that some people giggled when the screen moved to the $75-\mathrm{cm}$ position. When the screen came this close, some observers described the apple as "big and looming," 10 people said the image was now "easier to see," and there were reports such as "there are marks on the skin" and "now there is a stem." When the screen moved to $225 \mathrm{~cm}$, there were several spontaneous reports that the image was "less clear."

These results with a mental image are opposite to Emmert's results with an afterimage. To further investigate this finding, we essentially repeated Study 1 with different naive observers and with an imaging task that we considered might involve a more complex memory.

\section{STUDY 2: IMAGE THE HOUSE YOU GREW UP IN}

To get 20 people who could image the house they grew up in, 33 observers were tested. No suggestions were made about the size of the image. There were four conditions with five observers each. In each condition, the screen moved three times. For the two conditions with the initial position of the screen at $75 \mathrm{~cm}$ from the observer, the movements were (1) to
$150 \mathrm{~cm}$, then to $225 \mathrm{~cm}$, and then back to the $75-\mathrm{cm}$ position; and (2) to $225 \mathrm{~cm}$, then back to $150 \mathrm{~cm}$, and then to $75 \mathrm{~cm}$. For the two conditions with the initial screen positions at $225 \mathrm{~cm}$, the movements were (3) to $150 \mathrm{~cm}$, to $75 \mathrm{~cm}$, to $225 \mathrm{~cm}$, and (4) to $75 \mathrm{~cm}$, to $150 \mathrm{~cm}$, and to $225 \mathrm{~cm}$. At each screen position, observers reported "any change" in the image. The experimenter also asked the observer to "locate" the image by instructing her hand movements, as in Study 1. This provided height and width estimates without mention of size, although this may have given some observers the idea that size was of interest. The mean height estimates are shown in the upper function in Figure 1. One subject's height estimates, recorded each time as screen height, were that the image overflowed the screen at every screen distance; this happened to be the one observer who grew up in an apartment house. Meaningful width averages are not available from this study. This is because 11 of the 20 observers reported that the image overflowed the $76.2-\mathrm{cm}$-wide screen when the screen was up close. For both height and width size estimates, the image was measured to be smaller when further away for 17 of the 20 observers; 18 observers spontaneously verbalized this same relation between size and distance.

Consistent with the results of Study 1, 11 people reported more detail in the image when the screen was close. As examples, some commented they could now see detail in the bricks, and one person reported paint that had spattered on the front porch. Fifteen observers spontaneously described the image size change as a result of self-movement. They reported that seeing the house grow larger when the screen approached was like "walking up to the front door," and that seeing the house shrink when the screen receded was as though they had backed across the street and were viewing their house from the neighbor's yard. No one reported such a metaphor in imaging the apple. Also, 11 observers in this study, and none in Study 1, reported context in addition to the instructed object. As they "walked back" from the house (i.e., as the screen receded), they made such statements as, "Now I can see the corner of the neighbor's house," "Now I can see the driveway," and "There is the magnolia bush in the yard" (even though that bush had been cut down some 10 years earlier).

\section{CONCLUSION}

We asked people to visually imagine an object. If what they generated was indeed some analogy to a memory of just the instructed object, there is no reason to suppose that this already generated image should change in size when the screen changes in distance; there is also no reason that uninstructed 
context should be reported in the image, or that context should appear or disappear depending on screen distance. Perhaps what people generate is not some fixed image of an object. Rather, perhaps they generate a perspective from which to view (in some metaphorical sense; see Anderson, 1978) their memory, and this perspective is what changes when the screen distance changes.

This idea of a perspective would account for the reported image changes that accompany screen distance changes. By this idea, context in the mental image (the house) is not generated as the screen recedes; rather, the context for the remembered scene was there all along, but now it can be "seen" because the field of view has increased. Sometimes, as with the apple, the visual memory is of an object that has no particular context and the memory is thus viewed in isolation. However, appropriate instructions might result in report of context here too (e.g., "image an apple on a tree").

We do not yet know how or why screen movement produces this apparent perspective change. Whatever the process, it has similarities to optical systems, such as a zoom lens, that are constructed with variable focal length. With such optical systems, there is greater resolution (greater magnification) in the image, and less width of field, when the viewpoint is near than when it is far away. Whatever the reasons for these data, the essentially identical results of these two studies are not consistent with Emmert's law. Mental image size decreases monotonically with screen distance. We call this Emmert's imaginal law.

\section{REFERENCES}

ANDERSON, J. R. Arguments concerning representations for mental imagery. Psychological Review, 1978, 85, 249-277.

EMmert, E. Grössenverhältnisse der Nachbilder. Klinische Monatsblätter für Augenheilkunde, 1881, 19, 443-450.

KosSLYN, S. M. Information representation in visual images. Cognitive Psychology, 1975, 7, 341-370.

ShePARd, R. N. The mental image. American Psychologist, 1978, 33, $125-137$.

Shepard, R. N., \& MEtzler, J. Mental rotation of threedimensional objects. Science, 1971, 171, 701-703.

(Received for publication November 11, 1978.) 